\title{
Juntos: rituales, placeres y política de cooperación
} SENNETT, Richard. Juntos: rituales, placeres y política de cooperación. Trad. M. A. Galmarini. Barcelona: Anagrama [Título original: Together, The Rituals, Pleasures and Politics of Cooperation, New Haven: Yale University Press, 2012].

FERNANDO TULA MOLINA

\section{Resumen}

En este libro, Richard Sennett identifica las premisas de la cooperación en la sociedad contemporánea y como la cooperación ha sido políticamente moldada. Dividido en tres partes que incluyen una descripción de la evolución de los rituales de cooperación empezando en la época medieval, el libro trata de la naturaleza de la cooperación, de por qué se ha debilitado, y de cómo se podría fortalecer. Palabras clave: Richard Sennett. Solidariedad. Reciprocidad. Cooperación.

\section{Together - the Rituals, Pleasures and Politics of Cooperation}

\section{Abstract}

In this book, Richard Sennet examines the premises of cooperation in contemporary society as well as how cooperation has been politically shaped through history. Divided into three parts, including a description of the evolution of cooperative rituals starting in the medieval times, the book deals with the nature of cooperation, why it became weak, and how it could be strengthened.

Keywords: Richard Sennett. Solidarity. Reciprocity. Cooperation

\footnotetext{
* Universidad Nacional de Quilmes, Buenos Aires (Argentina)
} 
Este estudio parte de la constatación de que "estamos perdiendo las habilidades de cooperación necesarias para el funcionamiento de una sociedad compleja" (23); el cortoplacismo y la superficialidad propios de las transformaciones en el trabajo moderno "debilitan los vínculos institucionales" (22), por lo que, mientras en teoría las instituciones modernas favorecen la cooperación, "en la práctica la dificultan" (21), entorpeciendo uno de los componentes fundamentales del desarrollo humano (29).

Sennett explora las diversas aristas de la solidaridad (a partir de la concepción simmeliana de socialidad) "no como acción conjunta, sino como consciencia mutua" (62). A partir de aquí ensaya una distinción entre la izquierda política y la izquierda social; mientras la primera sigue una estrategia dialéctica, desde arriba, y utiliza la cooperación como un instrumento, la izquierda social ve en la cooperación un "fin en sí mismo", por lo que busca una construcción dialógica, desde abajo (71). Basándose fundamentalmente en la experiencia de los organizadores comunitarios, Sennett rescata la importancia del lema "asistir, no dirigir" (83); la protesta política estructurada se ve como "insuficiente para reparar los daños provocados" (84), no sólo por la asimetría de las actuales estructuras organizacionales, sino por la falta de responsabilidad, autoridad y compromiso de la élite que las gobierna.

Un tema central de su estudio es la posibilidad de lograr un equilibrio entre competencia y cooperación, evitando que la primera se interponga en el camino de la segunda (97). En primer término, hay que tener en cuenta que tal combinación no es imposible, como lo muestran los deportes y la música colectiva. Por otra parte, la ira y agresión propios de la competencia "deben equilibrarse con los impulsos de buena voluntad" (98); debemos transitar hacia este equilibrio no sólo en cuanto a las relaciones sociales, sino también con relación a la naturaleza; el equilibrio "ha desaparecido y hay que reestablecerlo" (105). 
Para este análisis ofrece un modelo de los intercambios sociales articulado en cinco tipos:

1. Altruista: implica autosacrificio que da forma a "su sentido de actuación personal" (111).

2. Todos ganan: se evita la confrontación aprovechando las ambigüedades; se valora la informalidad y los intercambios "cara a cara" (114, 116).

3. Diferenciador: los actores advierten sus diferencias; se centra en lo que cada cual aprende de los otros (evita la comparación odiosa y fomenta la cooperación) (123).

4. Suma cero: lo que uno gana el otro lo pierde; se basa en la competencia, pero debe dejar algo al perdedor "para que halla nuevos juegos" (126).

5. Ganador lleva todo: eliminación de los competidores; lógica del monopolio y el capital. Hay que ponerle fin.

Desde el punto de vista sociológico, su observación es que "en las relaciones humanas, la reciprocidad disminuye en los extremos de este espectro" (138), mientras que "en su centro la cooperación establece las reglas básicas" y define qué cosas tienen un valor especial "que justifique competir por ellas" (139). El equilibrio a reestablecer puede ser entendido como un equilibrio ritual; Sennett ya tiene una obra previa sobre este punto, donde su argumento se desliza desde los rituales de cooperación en el taller hacia propuestas de rituales sociales que, por medio de la cooperación, favorezcan la convivencia.

El ritual es lo que gobierna nuestra civilidad. Sennett hace referencia al manual del cortesano escrito por B. Castiglione (1478-1509) para valorar la importancia de la cortesía, con el fin tanto de "prevenir que un conflicto crezca en espiral hacia la violencia", como de constituir una "alternativa frente a la inmediatez con que el caballero se sentía ofendido" (179). En 
nuestros tiempos, en los cuales "el capitalismo ha roto el equilibrio entre competencia y cooperación" se vuelve necesario "renovar los recursos actuales para la cooperación" (186). El modelo del taller, de discusión abierta que analiza de modo conjunto problemas, procedimientos y resultados puede servir como referencia "para la discusión social viva" (184).

Sennett también lleva a cabo un uso argumentativo lúcido de la noción china de "Guanxi", entendida ésta como una "red de apoyo informal, más allá del rígido círculo de reglas y regulaciones preestablecidas" (192). Utilizará este concepto para contrastarlo con el sentido cortoplacista y superficial que damos en occidente a las relaciones sociales. De modo opuesto, el Guanxi está "destinado a ser sostenible, a pasar de generación en generación"; quienes pertenecen saben que recibirán ayuda (y deberán prestarla) "a quien lo necesite con independencia de su posición en la jerarquía social" (193). Claramente subyace una antropología no-occidental, en tanto que "quien se enorgullece de no pedir ayuda es considerado como un ser humano muy dañado" (194), y "quienes pertenecen no se avergüenzan de su dependencia". Esto marca un nítido contraste con "la idea de autocontrol individual de la vida familiar y empresarial moderna" (193).

Pero estas nociones tienen un objeto a analizar: la desigualdad propia de nuestra sociedad de consumo, la cual comienza considerando desde la edad infantil. El mercado para el consumo infantil es de un inmenso crecimiento (EEUU: 6,000 millones de dólares en 1989 y 170.000 en 2002). Tal mercado se construye a partir de dos elementos. Por un lado la "ansiedad de estatus" que tiene como objetivo, "superar el resentimiento de la invisibilidad y la marginación" (202); y por otra, la "necesidad de inculcar el deseo por lo que no tienen" (200). Esto se potencia con tecnologías como Facebook, dado que se confía menos en la publicidad efectiva que en la que se "asocia a la amistad y a las relaciones afectivas virtuales" (204). El problema es la "naturalidad con la que los niños toman la desigualdad", lo cual les genera una dependencia mayor al consumo (195). 
El esquema de su tesis es un triángulo social, cuyos lados son "el respeto muto, la autoridad ganada y la cooperación en momentos de crisis" (211). La tesis es que este triángulo "crea entre jefes y trabajadores una civilidad que va más allá de la cortesía” (211). En nuestra sociedad este triángulo debe ser reparado/reconstruido frente a las consecuencias de un capitalismo que ha conseguido "alejarse de las instituciones estables y del trabajo fabril" (222). La crisis surgida en 2008 llevó a los empleadores a ver el ideal de trabajador en el "consultor de habilidades transportables y de vínculo temporario" (229). De este modo, el tiempo laboral se tornó precario e inestable, actuando como "ácido que corroe la autoridad, la confianza y la cooperación" (231). En perspectiva histórica Sennett realiza una suerte de etnografía de este triángulo social, distinguiendo aquella forma primitiva (centrada en las buenas maneras y la diplomacia) de la forma actual, "donde las buenas maneras resultan insuficientes y es necesario avanzar al ámbito de la informalidad". Lo importante es que en ambos casos la civilidad consiste en "prestar seriamente atención a los otros" (253).

Sennett también establece un contraste con relación a la autoridad ganada. En el taller la autoridad "concierne más a la competencia formal o técnica que a habilidades de liderazgo", y supone diálogo abierto y "voluntad de asumir responsabilidad en nombre del grupo". Esto es lo contrario de lo que sucede en la cúpula empresarial: "cuando va bien es por méritos propios, y cuando no, se culpa al sistema" (246). Sennett realiza un cálculo interesante sobre la cantidad de personas que pertenecen a tal cúpula. Antes de 2008 las finanzas globales estaban dominadas por 5 firmas contables, 23 estudios jurídicos, 16 Bancos de Inversión, 6 Bancos Centrales y 2 Agencias de Calificación; en su cuenta esto suma 6000 personas, a las que se puede agregar un círculo "cara a cara" en razón de 1/10 lo que daría 60000 personas a fines de 2007. Aquí estamos, por el contrario, frente a un caso de ausencia o "vaciamiento de autoridad". 
Esto se agudiza en EEUU donde "la red de apoyo a trabajadores en paro es débil", y donde la cultura individualista "enfatiza la responsabilidad personal" en contra del control estatal (251). El punto que Sennett quiere destacar es que "la percepción de ausencia lleva a las personas a sentirse tratadas con indiferencia" (250); una falta de Guanxi (252). Así, en definitiva, nos enfrenta con la siguiente tensión sobre cómo entender el tiempo de trabajo: por un lado a partir "cortoplacismo de los accionistas que presionan cada vez más a las empresa a hacer las cuentas cada 2 o 4 meses" $y$, por otro, en referencia al Guanxi destinado a trascender los eventos particulares y donde "no hay ahorro de eficiencia" (240).

Sennett estudia, además, los motivos que conducen a la falta de cooperación, y luego las maneras en que ésta podría ser revitalizada. Para lo primero, utiliza la observación de A. Tocqueville en su recorrido por tierras americanas: "cada persona se comporta como extraña al destino de todas las demás" (266). Sennett agrega que, "cuando la autocomplacencia se une al individualismo, la cooperación se atrofia" (265). Por otra parte, la "ansiedad de estatus convierte "la diferencia en desigualdad" (267). De este modo, la vanidad y la indiferencia "deforman el carácter entendido como comportamiento responsable con los demás" (270).

El reestablecimiento de la cooperación es explorada por Sennett con relación al trabajo físico y la conducta dialógica propias del taller. Su tesis es que la sociedad moderna "tiene necesidad urgente de reparación", actividad que busca orientar "a partir de la reparación en el taller" (282); allí se valora la "tendencia a la simplificación" como estrategia frente a la complejidad, al igual que en el arte y en la ciencia (punto de contacto con los actuales planteamientos decrecentistas, aunque no haga otras referencias). Para tal fin es necesario entender el ritmo de las habilidades humanas, el cual pasa por tres fases: hábito, cuestionamiento del hábito, reinstauración del hábito (284). Será este ritmo del desarrollo de las habilidades el que se "convertirá en ritual" (285). 
La gestualidad es un componente importante en el proceso de simplificación de las conductas en el taller; a veces "la exhibición visual tiene más importancia que la instrucción verbal" (293) y, en general, para comprender el acto "necesitamos ver el gesto corporal" (problemas de los manuales técnicos). La colaboración propia del taller, su informalidad y el carácter abierto de las conversaciones van ligadas a "un bien visceral opuesto a la tensión de la ansiedad" (293). Su análisis lo lleva a concluir que "a mayor gesticulación, mayor intensidad emocional de la informalidad" (294).

¿Cómo comportarnos frente a las resistencias que aparecen en la práctica? Para responder a esta pregunta recurre a dos imágenes. La primera, otra vez oriental, proveniente del Zen: "El arquero experto deberá dejar de luchar para dar en el blanco, y estudiar el blanco en sí mismo, la precisión del tiro vendrá a continuación" (297). La segunda será la de los expertos cortadores de madera en un taller de luthería: "explorando los nudos siempre se aprende algo de la madera blanda" (298). En ambos casos se trata de tender hacia la resistencia mínima, con una actitud abierta y conciente. Sennett las utiliza para una tesis que puede ser tanto política como personal: "la autoafirmación mínima nos abre a los otros" (298). De este modo, a través de la ironía sobre uno mismo y la minimización de la agresividad, se alcanza la conducta dialógica donde el intercambio diferenciador pasa a primer plano (298). La experiencia social dialógica constituirá un "conocimiento encarnado" en el gesto social. Su sugerencia es que "comportarse con la fuerza mínima es una experiencia sensorial en la que nos sentimos cómodos con los demás", lo cual es más que una metáfora (299). Tanto física, como mentalmente, el uso de la mínima fuerza "nos evita el aislamiento al que conduce la ansiedad... y socialmente este placer nos llega con alegría" (299).

Su estudio busca abrir nuevas perspectivas en la diplomacia cotidiana, es decir, en el trato diario con personas "que no se entienden, con las 
que no es posible relacionarse, o con las que hay conflicto"; y ello con el fin de evitar el aislamiento y "mantener la conexión social con los demás", a través de la cooperación indirecta. Ésta última es entendida en los términos de T. Kheel como "cobertura simbólica" que permite visualizar que siempre algo se puede hacer, aunque esto sea "postergar el conflicto (a veces para siempre)" (326); una defensa del punto de vista propio "sin que el otro se sienta acorralado" (333). Al respecto estudia los rituales diplomáticos de bout de papier y démarche, los cuales se abstienen de toda acción asertiva mediante el uso del subjuntivo, "resultando útil tanto a fuertes como a débiles". Con ello se abre tanto la posibilidad de que "personas hostiles se mantengan conectadas", como de "comportamientos alternativos al simple consenso" (340). La diplomacia "neutraliza ciertos aspectos para que otros puedan pasar a primer plano" (344).

Ya en su último capítulo Sennett se refiere al pasado como tarea inacabada, donde se plantea también la posibilidad de "mantener la moral alta en circunstancias difíciles", y donde la convicción de los principios se conjuga con la necesidad de "actuar con cuidado" en la práctica (249). Las prácticas de cooperación brindan un refugio "frente a la generalizada agresión del ijódete!", por lo que podrían constituir "la semilla para un nuevo tipo de conducta más abierta que defensiva" (350), lo cual, en definitiva, deriva en la búsqueda de comunidad. Y aquí Sennett establece una distinción necesaria en el camino seguido por el conservadurismo moderno (especialmente en Gran Bretaña), y la izquierda social. En ambos casos se valoran las virtudes de la "vida local", pero mientras en el primer caso se supone que "el capitalismo proveerá todo lo necesario para la vida local", en el segundo no. La izquierda social sabe que "cuando a una comunidad se la despoja de dinero, se vuelve difícil conseguir voluntarios". La visión realista es que el comercio minorista está en manos de las grandes cadenas, lo cual succiona los recursos de las comunidades 
locales. En 2000 "por cada dólar gastado en el Harlem, sólo 5 centavos quedaban en Harlem" (359).

¿Como se podría desarrollar un sentido de finalidad interior mediante la cooperación comunitaria? La idea de Sennett es que a largo plazo "la vocación comunitaria" resulta frágil, por lo que de lo que se trata es de una "relación con nosotros mismos", entendiendo la idea de compromiso no de un modo rígido, sino como un "mapa de rutas de lo que uno haría" (365). El fundamento de esta actitud puede residir en la fe, o en la búsqueda de superación o cura personal. Como decía A.D. Gordon (1856-1922): "El compromiso con los otros puede resolver problemas psicológicos íntimos" (374). Por su parte, Sennett introduce la idea de la informalidad como "placer social" haciendo referencia al líder socialista $\mathrm{N}$. Thomas (1884-1968) quien sostenía que "a mayor autonomía sin reglas ni gobernantes, mayor valoración personal y social" (379), y que "si bien no hay que ignorar los límites de la realidad, tampoco hay que dejarse definir por ellos" (382).

En definitiva, la cooperación no es una promesa de felicidad, sino un "proceso de ingreso en el mundo" en el que se valoran las relaciones cara a cara y sus límites" (383), una idea de "civilidad" en los términos de Montaigne como "una modestia exenta de vergüenza": si nos sentimos cómodos con nosotros mismos "también podremos hacerlo con los demás" (390). El nuevo capitalismo combinado con el individualismo le ha permitido al poder cortar los lazos de cooperación, "distanciarse y vaciarse de responsabilidad" (392). El individualismo no es sólo un impulso personal, sino "la ausencia social de rituales". En condiciones de crisis, la gente común se retrae sobre sí misma, pero aspira a algún tipo de solidaridad, la cual está pronta a ser satisfecha por "la solidaridad destructiva nosotros contra ellos". Aún así, nuestra naturaleza social "siempre nos permitirá una cooperación más profunda" (393)... juntos. 
Fernando Tula Molina - Investigador del Instituto de Estudios sobre la Ciencia y la Tecnología (IESCT), Universidad Nacional de Quilmes, Buenos Aires (Argentina). $\gg$ ftulamolina@gmail.com

Recebido em: 17/09/2013 Aceite final: 07/11/2013 